\title{
Interfaces
}

\section{Photography In/Between Media Formats: The Work of Format from Magazines to Books, from Horst. P. Horst to Henri Cartier-Bresson}

\section{Alice Morin and Jens Ruchatz}

\section{(2) OpenEdition}

Journals

Electronic version

URL: https://journals.openedition.org/interfaces/2234

DOI: 10.4000/interfaces.2234

ISSN: 2647-6754

Publisher:

Université de Bourgogne, Université de Paris, College of the Holy Cross

\section{Printed version}

Date of publication: 12 July 2021

ISSN: 1164-6225

Electronic reference

Alice Morin and Jens Ruchatz, "Photography In/Between Media Formats: The Work of Format from Magazines to Books, from Horst. P. Horst to Henri Cartier-Bresson", Interfaces [Online], 45 | 2021, Online since 12 July 2021, connection on 15 September 2021. URL: http://journals.openedition.org/ interfaces/2234 ; DOI: https://doi.org/10.4000/interfaces.2234

This text was automatically generated on 15 September 2021.

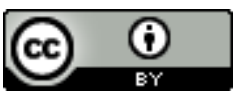

Les contenus de la revue Interfaces sont mis à disposition selon les termes de la Licence Creative Commons Attribution 4.0 International. 


\title{
Photography In/Between Media Formats: The Work of Format from Magazines to Books, from Horst. P. Horst to Henri Cartier-Bresson
}

\author{
Alice Morin and Jens Ruchatz
}

\section{Introduction}

1 The publication, in 1944, of the retrospective Horst. Photographs of a Decade by Horst P. Horst, which covered a selection of photographic realizations without foregrounding an overarching topic, was unusual for the time ${ }^{1}$ - although the genre would come to gain more prominence a decade later, as exemplified by Henri Cartier-Bresson's Images $\grave{a}$ la sauvette (1952) and an ensuing string of such publications. ${ }^{2}$ Its cover art sets Photographs of a Decade further apart, as it forges a salient feature out of a fashion image. The classical evening dress's upright design, unframed and full page, is bolstered by the verticality of the setting and echoed in the layout that spells the author's name in large, white, serif capital letters.

2 This design is hardly irritating to the contemporary eye; yet it bent the format conventions of the time. It did so by putting forth a fashion photograph when the genre, publicizing the ever-changing appearance of commercial goods, was not commonly subject to transfer into book publication, let alone on the cover. ${ }^{3}$ Furthermore, when it was first published as a fashion illustration in the American and French issues of Vogue (respectively March $15^{\text {th }}$ and April 1938), the picture was not even deemed spectacular enough to make it on the magazines' covers. In the book's introduction, Horst motivates the transformative media transfer, predicting that ephemeral fashion shots would turn into "clues of a vanished epoch" and painting himself into a sort of "social historian" (10). On the cover, harking back to this recent but vanished past, the elegant dress is enlarged to take up all the space, its presence 
enhanced in comparison with a magazine page, as no margins have been left. Similarly, the page featuring the photograph within the book (13) signifies its departure from magazine format regularities by placing it alongside a full white page - a "waste" of space that would be out of place in a commercial magazine. This luxurious white space by the side of the photograph can be interpreted as a claim to a higher, artistic value.

Throughout all instances, the reprinted photograph remains sensibly the same, and recognizably so: it is not cropped or reproportioned, it retains its rectangular shape, and variations in sizes are moderate. Yet, in its book performances, a fundamental recontextualization is enacted. Significant markers of the magazine media format that condition more than the mere size of the page - recede in favor of book ones such as the layout and associations, as noted above. Each set claims its respective mediatic allegiance: the book versions of the photograph are obviously from a photobook, the magazine ones from a magazine.

These print media, while distinct, are contiguous, as they build on the same technological basis and are distinguished "only" by the temporality of their distribution and uses, marking the magazine for transience and sequentiality and the book for durability and completedness (admittedly a major difference). Nevertheless, subsequent and/or further differing magazine and book format conventions have been long established through performative practice; they present each media with a distinct array of formatting options, from which deliberate editorial decisions can potentially arise. Formats condition content, hence our preoccupation with "format conditions": the treatments the photographs are subjected to, to ensure that their printed appearances fit the respective looks of a book or a magazine - namely, that they meet the expectations that converge in either format.

We set to reconstruct these conditions weighing on the appearance of the material on the printed page - here: photographic pictures - from a media comparative perspective. Print formats generally rely on informal, implicit and moving knowledge. To reconstruct these rules, we choose to turn to the published iterations that make them explicit. As in discourse analysis, we start from what is "positively" given, the result of the work of (a) format, i.e. the sequence of double pages of either a book or a magazine. Their respective media format conventions manifest in the regularities that run through a number of such instances (or performances), which can be worked out through observation. The invisible ensemble of cultural rules and conventions, stabilized by their recurrent display in texts and publications that perform and constitute their various format, can be traced in the serial work of the format rules across media productions: while format is detectable via the study of large corpuses demonstrating distinctive, underlying format conditions, following single pictures in their trajectory across format borders is another way of bringing these conditions to light. By paying attention to the "careers" of pictures and texts, ${ }^{4}$ it becomes possible to contrastively discern how the different formats in which they appeared worked to shape them. This paper offers a systematic contribution, proposing a way to deal with format(s) in $20^{\text {th }}$-century print culture, using format as concept and selected examples as tools to read the work of format, as exemplified by two case studies paying close attention to such "photograph careers."

When studying photography, the specific format conditions of various print media are especially relevant, because photographic pictures most often appear within the frame of another medium, usually not as photographic prints but as printed reproductions, in 
periodicals and books (as well as in the most ephemeral form of advertising in brochures or placards, etc.). The chosen case studies demonstrate typical uses of photography within some of the most prominent fields of its dissemination through printed mass media: fashion and photojournalism. Fashion as well as news magazines, which abundantly produced and published photographs, have been key players in print culture, in economic as well as circulation terms. The photographs under scrutiny were originally published in two such renowned magazines, Vogue and LIFE, ${ }^{6}$ initial publications that were representative of these magazines' specific media format conditions. But rather than any ontological qualities, it is their trajectories that offer interesting insights: both pictures successfully achieved distinction by selectively upholding certain format conventions upon their transfer from magazine to book, thus becoming visible. Consequently, they provide affordances whereby format conditions are rendered visible - whereas formats, to be effective, most often work to elude conscious perception.

\section{Format(s) in/as media theory}

7 Format started out as a very straightforward professional term used to distinguish different-sized books. ${ }^{7}$ Such sizes, or formats, were defined based on the sheet of paper used for printing, which could subsequently be folded one or several times, multiplying the number of pages (and decreasing the completed book's size). Since the initial paper sheet could vary in size significantly, this bibliographic concept of format did not simply refer to the size of the book per se, but to the standardized methods of determining sizes.

Distinctive standardized sizes subsumed under the term "format" later transferred on to pictures, in particular technologically-produced photographs. In the $19^{\text {th }}$ century, daguerreotype and glass plate processes alike distinguished full-, half- or quarter-plate formats. The current research interest in formats is motivated by the assumption that the choice of a particular size (for a book or photograph) is not circumstantial, but involves various cultural conditions and consequences. To give but one striking example, the carte-de-visite format, popularized around 1860, does not simply refer to the size of an eight-plate photograph (approx. $5 \times 8.5 \mathrm{~cm}$ ), but encompasses several distinct qualities and entails specific practices. What was called the "format carte de visite" by the French contemporaries implies a certain mode of production (taking eight pictures in a row on the same uncut plate, generally during the same session); a specific presentation (mounting the photograph on a $6.5 \times 10 \mathrm{~cm}$ card); a generic topic (portraits, typically but not necessarily full length); an innovative economy (the relatively modest price per picture rendered photographic portraits more accessible, creating a sort of mass market); a typical form of usage (giving one's picture to friends and acquaintances, collecting these portraits together with purchased ones of contemporary celebrities and displaying this compilation in an album) and, finally, a certain meaning (a symbolic (re)presentation of a more or less egalitarian view of bourgeois society). ${ }^{8}$ The carte-de-visite format was short-lived, though, and new formats like the larger cabinet card rapidly prevailed. Its situated and transitory fortune makes the carte-de-visite format a particularly poignant example of the complex multiple forces intersecting at a given point in history, tying the materiality of the photographic 
image together with a set of production, distribution and reception practices to constitute a recognizable format with a significant cultural role.

Up until the beginning of the $20^{\text {th }}$ century, speaking of "format" always meant referring to size. As noted above, size did not only matter as a material quality in itself: the way a publication was formatted anticipated certain intended reception modes (McGill 672) and formulated statements about its content - so much so that, in the early $18^{\text {th }}$ century, the editors of the English magazine The Spectator argued, only half-jokingly, that the size of a book should formally express the stature and value of its textual content: the more important the text, the larger the format that should be adopted (Spoerhase 27-28). In effect, certain print formats were meant to correspond with particular genres of literature (McGill 674).

During the $20^{\text {th }}$ century, the term "format" came to be applied to new media, thereby expanding its range of meanings. Moving on from purely material qualities, it came to designate also the implications carried out by formatting: the structuring and organizing of media practices and media content. When referring to the "immaterial" projected images of films or television, format could no longer refer to their actual size, but rather referred to their basic ratio, kept stable across different displays. As for the recent surge in format research, it stems from a broader understanding of the concept, shifting interest from matters of size to standardizations on a more general scale including the schematization of broadcast media programs ("format radio," "television formats") or the standard file structures of digital data.

11 Altogether, the Oxford Dictionary of Media and Communications lists eleven distinct meanings for the noun (Chandler and Munday, online). The same dictionary proposes a more general definition of format as a "distinctive design template in relation to the medium, genre, form, structure, style, and/or length of any form of mass communication." Recently, studies promoting "format" as a basic concept in media theory have sought a common denominator between the various interpretations of the term. Jonathan Sterne, author to the pioneering study MP3: The Meaning of Format, calls for a format theory to supplement media theory (7). German literary scholar Michael Niehaus has emphasized that "format" extends to the predefined constitutive rules according to which cultural events and artefacts are produced (49). Considered from a transmedial perspective, the concept of format intervenes at several levels: "Formats typically consist of specific sets of descriptions and requirements of how to arrange and present information"; the term "format" describes "a coherent pattern of order and composition - a standardized template for the organization of space, time or information according to some rhythmical, structural, aesthetic or volumetric rules" (Volmar et al. 7, 14). This emphasis on format as a "template" indicates that, to count as format, the organisation of content cannot result from an autonomous decision, but must resort to pre-established, habitualized patterns which are meant to be serially reproduced (Niehaus 49-50). All in all, formats are rules and conventions that organise and design media content in a formal and identifiable way.

It is important to note that formats do not flow naturally from media technology; they are social constructs ensuring the smooth operation of production, distribution and reception in a given medial context. Recent theoretical reflections in media studies have pointed out that formats do not just "emerge," but are "the results of conscious decisions" instead (Volmar et al. 10; see also Volmar 22-25). Format rules are described as institutionalized and static, acting as an external regulatory force, which appears as 
a non-negotiable given for media production and reception, once adopted (Niehaus $54-55,91)$. Sterne has argued that "[m]ost crucial dimensions of format are codified in some way - sometimes through policy, sometimes through the technology's construction, and sometimes through sedimented habit. They have a contractual and conventional nature" (8).

The degree of codification is dependent on the technological complexity of the medium. The format of a digital file cannot be modified at will by single users if it is to remain functional. In comparison, print is much less technicized. On the one hand, it relies on media technology in production only and requires neither technological infrastructure for distribution (apart from a functioning mail system) nor reception. ${ }^{9}$ On the other hand, letterpress printing is relatively undemanding in technological terms. Because print formats are neither heavily constrained by technology (in the way digital files such as MP3s or PDFs are), nor prescribed by institutional bodies or the big players of a monopolized industry (as is the case, for instance, for television), their format rules are mostly shaped by cultural practices, only conventionally prescriptive. That is, the format distinction between book, magazine and newspaper does not (necessarily) flow from technological innovations or the binding decisions of a few publishing houses. The format rules of print are disseminated as informal knowledge, which the practitioners of book production and the book trade acquire by listening to their peers or from observing their production. Thus, print formats are typically codified in the form that Sterne calls "habit" and are more open to change than more institutionally stabilized types of format. ${ }^{10}$

14 The rigidity and mandatory degree of format rules also vary according to the level at which they form. At the level of singular magazine titles or book series, what we set out to call "special format" can actually be the result of conscious decisions to design a distinctive layout and structure as a means of branding, which sets a single periodical title apart from its competitors. The serial work of the format, expressed through (relatively) stable, recognizable elements such as given columns, categories and layouts, balances the ever-new content of each issue, crystallizing a given magazine's identity. ${ }^{11}$ Diachronically, the format secures coherence throughout series; synchronically, it presents a distinctive profile that sets it apart from other special formats. "Generic formats," which organise content and form in relation to a common genre, emerge in time and stabilize by organizing reflexive expectations, within which magazines producers tentatively guess what their audience expects, while readers tentatively guess what their counterparts in production expect them to do. ${ }^{12}$ Book genres and magazine genres each share common parameters organizing and displaying their content. The same goes for the most abstract level of the "media format," which refers to the way in which different print media typically appear. Format operates on the form of a medium, and in turn takes form through the performative uses of said medium. In order to remain operable and accommodate varied productions in print culture, this level of formatization prescribes only very basic rules and must be resistant to singular cases of divergence. ${ }^{13}$ Despite its formal vagueness, the format difference of book and magazine plays a major part in print culture, distinguishing, for example, texts and pictures to be kept (in books) from ones to be discarded (in periodicals).

15 Let us stress that this paper is not concerned with the substance of the format, whatever that would be, but with the work of format, i.e. with what it does. At their 
respective levels, special, generic and media formats, similarly to the more evidently external and formalised formats of other media, organize content in a formal and serial, repetitive, schematic way, with regard to the specific conditions of the printable double page. Thus, we embrace a broad definition of the concept of format, expanding from the page size of the bibliographic format and taking into account any formal parameter that organizes the content in print media in a manifest way. We believe that various constituent complexes come into play in the making of print format conventions, and that these are not stable but evolutive and performative. Hence, we aim to show how format works, rather than to consider it as a static set of rules upon which to base our observations. Indeed, the formal aspects that are meaningful formatwise are not the same for every medium, genre or title. For example, fashion magazines display a significant number of successive editorial series uninterrupted by advertisements (the so-called "editorial well"), a significant gesture in a publicitysaturated context. By contrast, there is no equivalent in $20^{\text {th }}$-century illustrated news magazines. What becomes a characteristic trait in the formal organisation of a given format emerges only in its repeated and serial performance. Certain formatting options arranging content may be defining for one format, but may not apply at all to another. We ask: which structural elements can be factored in as defining, requisite and meaningful in a particular print medium at a particular point of time? How do they change over time or become reinforced? Observation of the printed material evidences how formatting decisions are made, amongst a range of delineated options available for content display.

\section{Transferring photographs: seminal examples in different media contexts}

16 The transition of photographs from one print medium to another is a particular case where media borders are made more distinguishable. Magazines and books were the two major media for the distribution of photography in the $20^{\text {th }}$ century. They provide us with an especially interesting arc, because they are altogether competing and converging media. They are interrelated in more than one way and together they structure an image economy. Until recently, professional photographers typically gained exposure through inclusion in magazine publications, such visibility then enabling them to publish books. This circuit exemplifies the fact that, whereas books are considered higher up in the cultural hierarchy, magazines tend to be higher up on an economic scale. Images thus partook in a pattern of distribution (and production) offering several configurations. This worked to the benefit of both media, affirming each medium's position within a network of cultural productions - and providing an incentive to buy the same picture several times, for different reasons. Magazines and books appear rather complementary in crystallizing photography's cultural importance and uses for a large audience. However, this also means that they have had to differentiate themselves from each other - a predication in which formatting photographs in distinctive ways played an important part.

17 Concerning photography, inclusion within print media has major implications: one of the format conditions of print media is that they tend to erase photography's own formats, the materiality of the former overriding that of the latter. The size of photographs on the double page, but also the constellations they form with peritexts, 
paratexts, peri-images and para-images,${ }^{14}$ as well as their placement and sequencing within the issue or book then all become utterly signifying, each decision formatting the said images into differing contexts. The two cases studied here performed significant reformatting from illustrated magazines to monographic books, shedding light on both media's format conventions through comparison.

\section{Horst P. Horst's "Corset": formatting a seminal photograph} photograph with these constraints in mind: the picture was set to report and stage a recent trend, in a legible and attractive way. At the level of the image, the magazine format conditions were scrupulously followed, the templates upheld. For one, the corset representation is a close-up, where details such as the lacing work stand out, for the reader/viewers to admire. ${ }^{16}$ The chosen angle of representation, from the back, also adds to the photograph's style. Due to its subtle play with light and shadow, Horst's Corset in Vogue is an arresting photograph; its allure contributes to the magazine's prestige, founded upon the artistry of its collaborators. In fact, producing beautiful pictures is crucial to Vogue, and one photographer's style should be recognizable in its pages. But this stylish shot is only one piece of a polyphonic whole, arranged by the magazine's superseding editorial composition.

21 The photograph is also subjected to a specific arrangement of content in the double page, series and issue of the magazine, all orchestrated according to its format rules. The double page is somewhat crowded, as was typical at the time. It features four photographs arranged thematically and spatially, under the title "Waist-Lines, Ltd., Paris, France." A frontal view the same Detolle corset as our case photograph, and an 
additional piece, both photographed by Horst in the same setting, are included. As the text preaches exercising in order to keep one's waist slim, a last image of such exercises, by American photographer Toni Frissell, is added into the mix on the bottom-left handside of the page, tilted.

Such a layout is made possible by technological preconditions: the generalization of reproduction through the half-tone process cut ties with the negative. ${ }^{17}$ The size and disposition of photographic pictures became totally malleable, which in turn produced new options to adapt pictures into an unlimited range of sizes and shapes, allowing for a complete manipulation of the material in the layout. Whether a picture would appear full page or as a miniature could thus be decided upon by the editors and graphic designers, according to template conventions. Here, while the size and disposition of these photographs indicate that the Corset is the most important feature in the grouping, it is by no means an isolated element in the double page. The malleability of photographic material, as well as the (typical) display of multi-authored photographs on a same compositional unit, strongly signal that the authorship of the feature lay with the magazine, responsible for the composition and title of the page.

The special format conditions of the fashion magazine Vogue are manifested in the sequencing choices too, which present different variations on a fashion accessory in a distinctive yet decipherable style, and in a particular order. Constraints of readability and thematic coherence - developing from commercial necessity - but also of style, all intricated, govern the double page and suffuse the entire series, the issue, and even the magazine run. The collection report itself articulates 16 double pages, associating the photograph with other fashions (Velásquez inspirations, velvet, plaids...). As the corset is lingerie, the photograph is published in the last pages, following the hierarchy and format logics of the magazine, which first promoted evening dresses, such as the one later chosen for the book's cover. But the corset trend is mentioned nominally in the opening lines of the series and even in the table of contents. The emphasis is put on the trend itself, which figures throughout the magazine in text, photographs and drawing. ${ }^{18}$ Horst's picture is but an illustration of this trend, which represents a red thread explicited in words and taking shape spatially, for a better communication of the magazine's messages.

At first sight, the book version of the Corset seems almost identical to the magazine one: it is neither cropped, nor resized. It remains a (simili) full page - and thus consequent - feature. In fact, because the book size closely follows the magazine's, the size of the image remains practically the same. ${ }^{19}$ The most notable change resides in its contrasting: in the book, the photograph is significantly darker, the black, white and grey tones standing starkly against each other. The rich texture of the black tones reproduced in the book is emphasized by the upscale matte paper used as well as by the choice of a somewhat colorful black with a slightly purplish hue, distinguishing it from the straightforward, "blander" color of the magazine. ${ }^{20}$ This contributes to laying an artistic claim on the book performance of the image. It obscures the stage set, and even the corset itself, ${ }^{21}$ to shift the emphasis on the sinuous lines of the (unknown) model's body, her shoulder and the texture of her skin and hair, as well as on the lacing, making the image emblematic of the sculptural qualities that Vogue's art director Dr. Agha praises as characteristic of Horst's photographic work in his preface to the book (6-7). The effect is also one of accentuated theatricality, a dramatic atmosphere furthered in the caption, which reads "The Mainbocher corset that shared headlines with the 
invasion of Poland. 1939." Delving right into the core recontextualization enacted by reformatting, this allows to situate the image within the argument of the book - laid out in the introduction - strongly anchored altogether around the photographer's style and around the war and the changes it brought about. By adding such peritext to this (and other) photograph(s), Horst adds value to his work by inserting it in a historical context. Interestingly, the book caption differs from the magazine's also in that it credits the corset to Mainbocher (the designer, or "author"), whereas the magazine attributed it to Detolle (the brand). Indeed, whilst the image remains more or less stable in the course of its transfer, the photograph's environment, on the page, in the section and throughout the book shows how it transfers into a distinct - and distinctly formatted - project.

The white space on the double page alone is emphatic. While book and magazine both feature the same amount of white space, in the former the Corset is paired with an oblong shot, and no other pictures are added to the page. This means that a long white strip expands on its left, a space sanctified as a frame of sort, the double page acting as a display site rather than a narrative unit as in the magazine layout. It speaks to a decidedly photobook design, where photographs expand as much as possible on the pages, conceived with their best presentation at heart. All the double pages in the book follow such a rule: they showcase only one photograph per page, a great many of them full page. The layout uses the varied-sized white spaces of the margins as respirations, meant to enhance the effect produced by the picture - and to emphasize certain pictures by extending their allotted space onto the opposite pages via white strips. Systematically and unwaveringly, the book format engages in bringing photographs to the center stage, sparking an immediate visual contrast with their magazine performances. One central format condition here is the book's regularity in content, and layout: size variety is reduced, the photographs are disposed on the page according to a small number of patterns (upper leftside or rightside corner, horizontal half-page, vertical full-page) and there is no tilting. The only limitation to the photographs' expressiveness is the size of the page itself (and the occasional caption inserted below some selected shots).

On account of the attention to each selected single photograph, typical for photobooks, the images become something more than fashion shots. The a posteriori harmonization of a miscellaneous body of (editorial) pictures, necessary to cohere it into a book, entails making choices in terms of layout, but also of image sequencing and organization in sections that strongly differ from the magazine's periodical and promotional logic. By loosely emphasizing thematic connections between the sections, expressed through the voice of the photographer in a few interspersed texts, the book's editorial choices are scripted as resulting from an artistic vision. Furthermore, pictures in photobooks were typically formatted in light of an overarching theme; here, the implied theme is the showcasing of the author's outlook on his own corpus. In this regard, Photographs of a Decade, while upholding the layout conventions of a photobook (centered around the glorification of the images themselves), presents its readers/ viewers with a shift from the typical argument underlying these books so far (a thematic one) to a monographic one unfolding the auctorial voice, and sets a template for how to format such a message. By doing so, it strongly departs from the magazine, the thematic double pages of which always stand as collections of miscellaneous 
material and voices (Beetham 24-25); and to which the very idea of a monograph is foreign.

In accordance with the logic of the book format, the photograph is thus re-nuanced, recaptioned, and repositioned within an auctorial context. By adhering to the aforementioned format markers of the photobook (use of white space, enlarged photographs, textual indications, sequencing according to its own subjective logic), Photographs of a Decade seeks to elevate the pictures it contains and raise their status by associating them with durability and artistry, recontextualizing them as documents and artworks altogether. This reformatting imbues the Corset in Photographs of a Decade with permanence (versus ephemerality) and with an aesthetic-historical value, transforming the status of the image. The book version of the Corset supports the idea of a photographer-author whose ability resides in fixating a moment - in this particular case, a moment exceeding the temporalities of fashion, cosmetics and portraiture further contributing to legitimize photography as a practice and a medium.

However, the book did not shy away from the original production context of Horst's photographs. It very openly credits Vogue (which, to this day, is copyright holder for the photograph). The book's formal indebtedness to the magazine is evident: a Voguelike font for the texts and a similar sans-serif page number are even used. This is even more clearly articulated textually, for example in the opening text of the section comprising the Corset, composed of beauty photographs. In this ambivalent report on magazine collaboration, Horst reflects upon the challenge in photographing for the editorial beauty pages and stresses the role of the editors: "When the beauty editor of a woman's magazine appeals to the photographer, it is almost never to show specific merchandise. She asks him to take a picture that will make every woman who looks at it long to have a beautiful skin..." (84). To fulfill this implicit vision, Horst indicates, he resorted to plunging into "the unconscious" and to materializing "the dream" (idem), drawing on his capability of turning the mechanical apparatus into an instrument of art production: "the camera in the hands of people with a developed pictorial sense is far from being an unbiased mechanical instrument. Impressions, sensations, attitudes make the world look like what we want to see," as he notes in a preceding commentary text (62). Editorial constraints thus appear sublimated through one man's talent, displacing the photographs from commerce to art. In doing so, the book argues, Horst (unknowingly) encapsulated a vanished epoch's charm - in the end negating collaboration, as the book format allows by foregrounding one author above all other editorial actors.

In that regard, nevertheless, Photographs of a Decade is also a thematic book (about a bygone era); a step in the transition from thematic to auctorial publications; an early manifestation of what the artistic monographic book would accomplish in the following years. At any rate, it displayed photographs in a much more durable way than a magazine would, while inscribing them into fixed and more homogenous narratives. Embracing the cultural hierarchy putting books over magazines proved to be profitable to both media, whether their producers were prominent or overshadowed contributors to the project - the book bestowing poise on magazine photographs, which in turn were reused over and over in several cultural outputs.

A formatting instantly identifiable as book-like was instrumental in this process, as photographs not picked up in books (and/or exhibitions) are unlikely to attain the sort of fame later achieved by the Corset. In the succeeding decades, magazines (Vogue in 
particular) as well as books consistently republished it, most often in anthologies or commemorative articles on (fashion) photography, either still granting it a full page, or making it into a vignette inserted into a continuum, or gallery of (fashion) photography (Vreeland; Hall-Duncan 65; Lawford 185; Bowles; Borelli). This continued circulation, as well as the ensuing pastiches and homages (most notably in Madonna's music video for her track Vogue), ensured the image's recognition and its association with the narrative brought about by Photographs of a Decade, which solidified in the process. What ultimately makes this photograph a particularly remarkable instance of transfer is indeed that its continued circulations have made it "iconic," completing a path sketched from magazine to book, and getting higher up the cultural hierarchy until the print media that disseminated it disappeared behind the image itself, its formatting obscured, yet still at work.

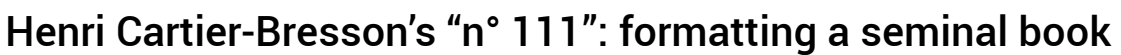
titled The Decisive Moment for its American edition) enjoys a seminal status, and contributed to the legitimation of photojournalism as art. Unlike the corset shot, however, its critical success was almost immediate, making its influence durable. When the book came out in 1952, Henri Cartier-Bresson was already a famous photographer. A co-founder of the Magnum agency, his photographic production as photo-reporter significantly expanded from 1947 on, and he spent the better part of the years 1947 to 1950 travelling in Asia, where he started to regularly collaborate with LIFE (Bair 2020, 75)..$^{22}$

Turning to photo-reportage meant complying with a well-established practice, the development of which is intertwined with that of the press and with the foundational genre of illustrated news magazines, bringing about enduring, though fluid, conventions. Yet Cartier-Bresson's inclination to cross over the continuum between editorial and artistic photography, to repurpose one into another (Chéroux 21-22), occurred here again in the restaging of his photographic works from magazine to book. Indeed, the photographer's background - his training in classical painting (which he hints at in the preface), his association with avant-garde artistic movements such as the Surrealists in the 1930s - and his trajectory, sanctified by a 1947 MoMA monographic exhibition and ensuing catalogue, made him especially predisposed to turn any of his photographic works over to the realm of "art." ${ }^{23}$ This institutional recognition is in fact the reason why he was granted an auctorial voice in his reportages, amongst which one made in Peiping (Beijing) just before the Communists took hold of the city, and published in the January $3^{\text {rd }}, 1949$ issue of LIFE magazine. The image of a blind fortune teller, numbered 111 in Images à la sauvette, initially published in this reportage (Fig. 1), with its significant differences between magazine and book performances, offers a visual explicitation of the reformatting operated in the transfer. 
Figure 1. Photographs by Henri Cartier-Bresson. "A Last Look at Peiping" (LIFE January $\left.3^{\text {rd }}, 1949\right)$, 16-17.

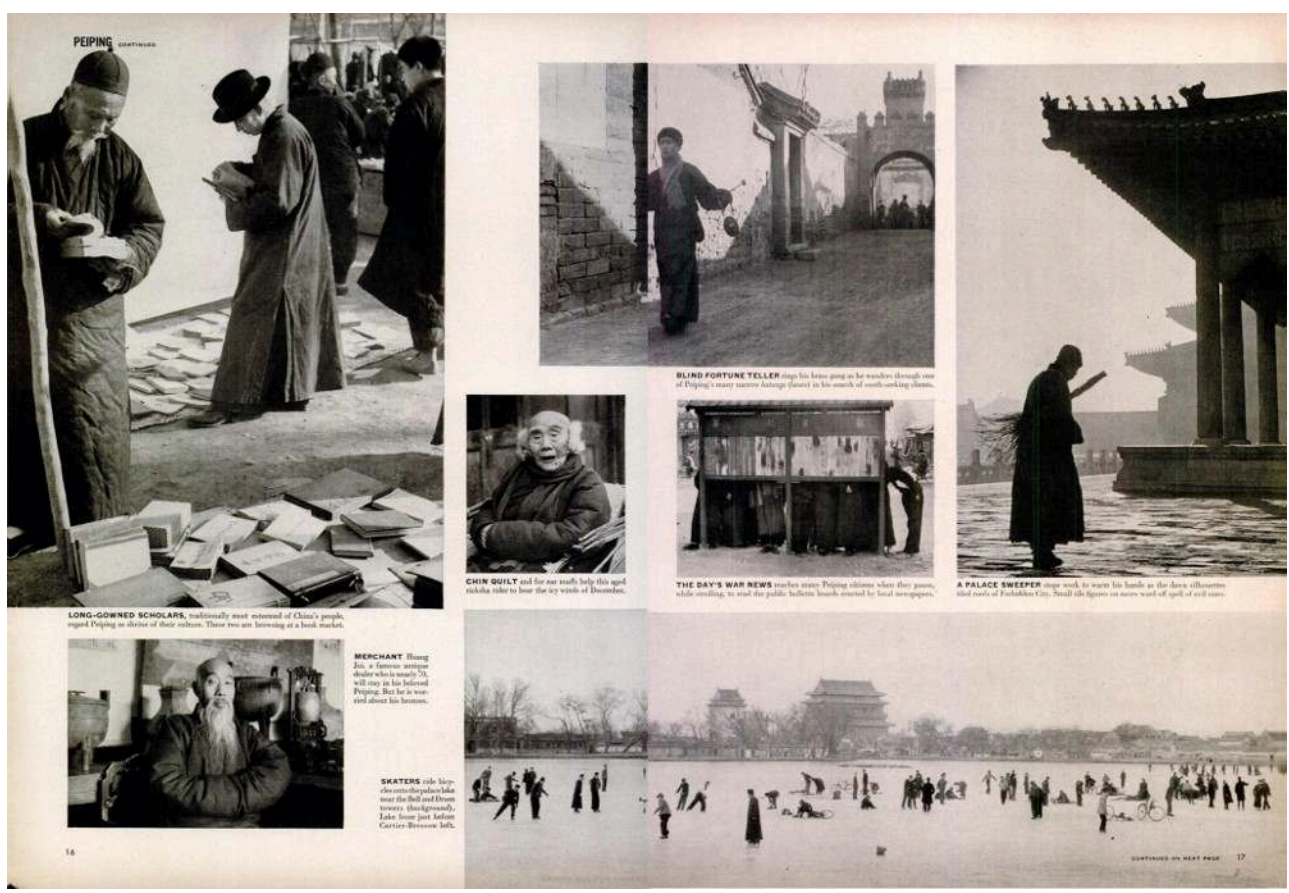

(c) Fondation Henri Cartier-Bresson / Magnum Photos.

The 1949 LIFE publication staged Cartier-Bresson as an author, but it also staged the reportage as its own initiative: "LIFE asked the famous photographer [...] to fly from Burma to Peiping for a last look at [the] city," state its opening lines (13). The story is, from the start, built up as an important piece of reporting by an important photoreporter; it is given a prime position as the opening feature, spreading on one full and four double pages right after the table of contents, uninterrupted by ads. Its 26 photographs, commented upon in captions based on Cartier-Bresson's words, ${ }^{24}$ depict everyday life in the capital just before the arrival of the People's Liberation Army. The overall aspect of the article is dynamic. Composed of many shots apparently snapped "on the move," it offers readers/viewers a close-up view on its topic, following in the photographer's footsteps across town. Displayed on the $4^{\text {th }}$ and $5^{\text {th }}$ pages (the second double page) of the reportage, the photo of the fortune teller spreads over the page crack, a layout choice that further emphasizes the depiction of a seized movement. The disposition of other photographs around it also contributes to bolstering dynamic readings: the 7 images, of uneven sizes and shapes, are disposed clockwise, inciting the eye to jump from one to the other in no particular hierarchical order - or to follow the spiral that runs from the top corner of the left page towards its bottom, then swerves to the right, to finally circle back upwards to the center, in order to "enter" the double page.

This brings us back to the fluid but enduring conventions central to news magazines. The genre crucially relies on photographic images but, more importantly, on staging them into a signifying whole arranged by the magazine - more precisely, by the person overseeing its editorial interests: the picture editor. This key figure selects images for publications, then arranges their sizes, framings and disposition on the double page, with the entire issue in mind, also deciding on their placement and the constellations 
they form with one another to convey the reportage's outlook on the news through such formatting. Here $\mathrm{n}^{\circ} 111$ abided by the editorial expectations and format conditions of the magazine, necessarily prevailing over the photographer's expression, no matter how much the latter was propped up within the former's pages. The "apparent author" had to comply with the magazine's conditions in order for his images to reach their audience by integrating a widely distributed title.

Figure 2. Henri Cartier-Bresson, Images à la sauvette. Paris: Verve, 1952, 122-123.

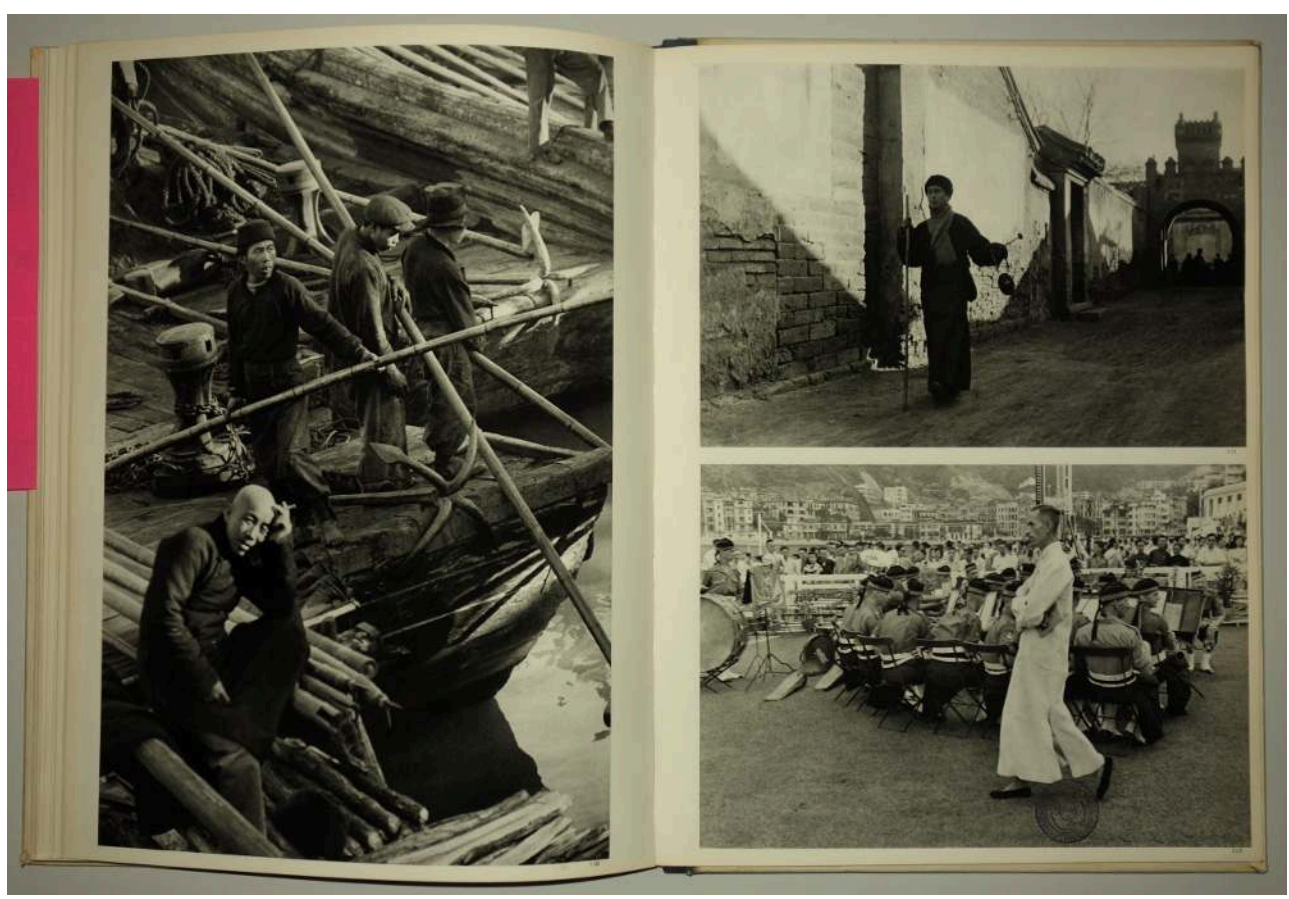

(c) Fondation Henri Cartier-Bresson / Magnum Photos.

The performance of the photograph in the book is in stark contrast (Fig. 2). Following the strict design of the publication, it occupies half a page, on the top-left handside of the double page. This layout is actually applied throughout the book, which only allows for three sizes of photographs (full double page, full-page and half-page). This simplification sets out to invisibilize the layout, which thus appears to be derived from the pictures. For their part, the captions are "pushed away" from the images into special booklets (inserted as the center pages and end pages) and the only text left on the photographic pages are the minuscule numbering of each picture. Even the white space between pictures and in the margins is reduced to its narrowest. Evidently designed to foreground the photographic image, this consistent and coherent minimal mode of presentation implements a strict design protocol. The layout of the book is meant to interfere as little as possible with the composition of the pictures, which the introduction by Cartier-Bresson stresses as a particular achievement for the ambitious photojournalist (or photographer) to strive for, thereby distancing the book from the dynamic work on the photographic material performed by a magazine's picture editor. He in fact mentions the work of photo-editors in a section about magazines (deemed "clients"), whose vision is sometimes at odds with the photographer's, in the same introduction: "c'est l'unité de la page qui prime et souvent la composition conçue par le photographe se trouve ainsi détruite" (13). He implies, indirectly but evidently, that the (monographic) book is the medium where the photographer can remedy magazines' 
intervention. The entire book presents itself as a counterpoint to magazines' work, and conditions. It is an "anti-magazine" of sorts, in which photographs need not comply with the print medium's format, the layout being organized around their own conditions instead.

The idea of an integrity to photographs runs through the book as a leitmotiv: it is highlighted in the introduction; perceptible in textual and visual choices, and in the (size) formatting the pictures are subjected to; and in the format of the book itself, in the traditional meaning of the word $(27.4 \times 37 \mathrm{~cm})$, which was chosen "for the layout to respect the original proportions of the negatives, whichever the preferred orientation" (Meizel §2). It is an unusually large size for a photobook, approximately equaling the size of the magazine..$^{25}$ It also, importantly, entails that Cartier-Bresson's Leica's $24 \times 36$ $\mathrm{mm}$ negatives are put back at the center of the layout concept, adapted to their optimal viewing requirements. The introduction also elaborates on the craft of photography: ${ }^{26}$ the photographer is depicted as a professional able to observe (and fixate) "reality" with his camera (6), by being (himself) present at the right time, in the right place and, most importantly, by his ability to compose the picture instantly - as the events unfold - in his head. For Cartier-Bresson photography, a combination of technical mastering and talent, is a process centered around the eye, trained for composition and capable to "measure" and "translate" a moment into "rigorous forms" (12-13). Once taken (if possible, in one or just a few tries), the photograph is not to be touched-up, edited or, in fact, reformatted (in terms of size and cropping). If it is modified, in the darkroom or graphic department, its integrity will be irremediably compromised $(9,13)$. The book is constructed as the perfect medium in order to optimally preserve his photographs, thanks to its perennializing properties, of which Cartier-Bresson was fully aware: "Magazines end up wrapping French Fries or being thrown in the bin, while books remain," as he put it (Ritchin and Naggar 25). ${ }^{27}$ Moreover, the regularity of the book format, which is, here, pushed to an extreme, is particularly well-suited to such a project and lends itself to a design where images become truly "monographic," definitely distancing themselves from the miscellaneity of magazines.

Images à la sauvette was edited in collaboration with and published by Tériade, specializing in fine arts books. ${ }^{28}$ The cover features a collage by Matisse rather than a photograph, immediately claiming distinction from other photographic books. This is, of course, a major break from book format conventions, whereby the cover illustration and the content are meant to be closely related: due to the distinctive unmiscellaneity of books, the cover can and should represent and announce the content. ${ }^{29}$ With this programmatic, demonstrative gesture, the book producers effectively (dis)placed the book into the realm of art publications; announced such a project; and affirmed its affiliation with other artistic enterprises, notably by Tériade. Composed of paper cutouts, the collage tends towards abstraction, abandoning formal and spatial referentiality to express an artistic truth. It could be interpreted as an invitation to contemplate photographs in relation to sensation, rather than representation. What has been described as Cartier-Bresson's characteristic use of pictorial "flatness" (Sichel 143) ties his and Matisse's work together into the modernist concept of the flat, twodimensional picture. The fact that, in between its covers, the book sets out to offer its format to photographs in order to display them in "ideal conditions" as artworks flows logically from such a cover. Much in the same way, both the high-quality process of heliogravure used to print the photographs ${ }^{30}$ - one very sensitive to the richness of 
grey tones - and the quality paper chosen for the book, work to weave art and craft into a high-end endeavor. Resorting to the best available techniques and professionals to showcase photography is a way to "respect its integrity"; it also results in elevating its status.

This positioned Images à la sauvette not merely as a photobook, but as a book on photography. Its publication enshrined the monograph as a site for the photographer to comment upon his work: just as in Horst's case, the "author's" voice was finally expressed. By commenting at length in the introduction on his working processes, Cartier-Bresson in fact expressed his views on photography itself, in terms of technique, practices and, implicitly, cultural value.

further layout choices unfold such a vision - in deliberate contrast to magazines. Getting back to $n^{\circ} 111$, the book actively engages in smoothening the dynamics of the images on the page. The magazine's ambulatory outlook is replaced by a paced out, almost meditative structured grid. Such a slower rhythm, diverging from the movement induced on the magazine's double page and sequencing of double pages, is built up by the sober look, as well as by the lesser number of photographs per double page (four being the maximum). This tentatively aims at slowing down reception and at making the viewing of the picture and/or the reading experience of the entire book more immersive. ${ }^{31}$ The organizational choices also stem from the structuring voice of the photographer. They place $n^{\circ} 111$ in the second of two sections. The first one presents diverse images from Cartier-Bresson's earlier career; $\mathrm{n}^{\circ} 111$ fits in the series composed of photographs taken in Asia after 1947, arranged according to the countries visited but also to aesthetic resonances rather than chronologically, indicating that the photographer's subjectivity apparently prevailed in terms of images sequencing, and experimenting. ${ }^{32}$

40 As in Horst's case, the displacement performed by reformatting, intertwining photography-as-documentary and photography-as-art, unfolds in two crucial steps: a reassessment of the message conveyed by a set of photographic works, permitted by the cohesion of the book as a complete object (versus the periodical being always "in the making"), and a "re-temporalization" of the photographs. The book transforms an element from a reportage - narrating a specific moment in history - into part of an oeuvre - a testimony to an artist's view of the world.

41 The respective content of the captions of $n^{\circ} 111$ in the magazine and book make such an operation explicit. The first one reads: "Blind fortune teller rings his brass gong as he wanders through one of Peiping's many narrow hutungs (lanes) in search of soothseeking clients," the second "Pékin, 1949. Peu de jours avant le changement de pouvoirs, un diseur de bonne aventure aveugle annonce son passage à l'aide d'un petit gong au son aigu." The magazine caption is to be supplemented with the other texts included in the reportage, from which it cannot be separated. In the book, however, the mise-en-page signals that the "caption" is not even mandatory reading, relegated to a booklet which requires extra effort to consult. The possibility thus offered to receive the photograph without a textual "explanation" severs its relationship to a concrete event. It can further be understood as an apology of the world view held by humanist photographers and propagated by the Magnum group: photographs are then less about the politics of a specific historical event, but more universalist in scope, claiming insights into instances of the general human condition. ${ }^{33}$ Moreover, by referring to the sound of the gong pictured, the book caption refers back to the "decisive moment" of 
the prise de vue as experienced by the photographer, and rendered through his photograph.

Such a visual and textual narrative promoting the photographer's eye both works to mythologize the photographic practice and to rewrite the actual unwinding of the reportage, concealing its collaborative dimension. As Nadya Bair has exhaustively documented, exchanges between the photographer and LIFE editors attest that, far from one (or a few) "decisive moment(s)," Cartier-Bresson produced several rolls of film while on assignment. From Peiping, for example, he submitted many shots, made after the picture editors' precise instructions. They later operated a selection, and the photographs published in the 1949 reportage were just a few amongst a vast available array (Bair 2016, 150-52). Bair contends that Cartier-Bresson validated the editors' choices by including three of their picks in the book - and he acknowledged their work, to a certain extent, in his introduction (Bair 2020, 77-78). It is for this reason that the present subject of analysis is $n^{\circ} 111$, aptly incarnating such a "decisive network" after the expression coined by Bair, while demonstrating distinct magazine and book properties with a remarkable economy of means. Yet the monograph format again readily obscures these central collaborations by positing the photographer as the one eye that captured the one image. Similarly, the very collaborations necessary to produce the book (with editors, translators, agents...) are erased (Meizel \$23), even more so than in the case of Horst. The visual and textual choices in the book make good use of the available format possibilities; they mark it as an authored whole, distancing the work from its editorial ties. Completed with an efficient publicity campaign directed at an artistic sphere sensible to the book's argument (Bair 2020, 207-9), this contributes to explaining the success of Images à la sauvette, which soon established itself as the seminal photobook for high-standard photojournalists, and a template for the display of editorial (i.e. commercial) photography as art (Chéroux 3, 18-19) thereby initiating in turn some new generic format conventions.

\section{Conclusions}

Cases in which photographs transferred from one medium to another inform our understanding of the work of format in these respective media. Rather than impacting the size and shape of the transferring photograph, ${ }^{34}$ in both studied instances, spatial and structural (or organizational) elements were the ones reformatted from one medium to the other, resulting in fundamental recontextualizations that charged the photographs in question with new, or refined meanings. In the process, the temporalities and memorialization processes of photography in the magazine and book media, as signified by their respective formats, were irremediably modified.

Formats are thus productively conflated with contexts. Contexts are textual environments, addressing the specific constellation between text and environment in a concrete case. ${ }^{35}$ Formats, by contrast, are reproducible and repeatable: they organize the constellation of text/picture and context by giving templates for how they should be positioned and arranged. The level of format organizes contextual relations. Recontextualizing photographs through media transfers is made possible because the organization and relations between images and their disposition on the page and within the media are not givens determined by the content and composition of the pictures themselves. Instead, they are formalized through the establishing of 
significant conventions at the interplay between production practices and (re)uses. This paper has been precisely interested in affordances where the agency of creative actors in a given cultural context have engaged in negotiations with the formative power of the format. They have made sizing, placement and layout decisions based on the magazine and book media formats (converging with generic and special formats, especially in the case of Vogue and LIFE) that allow for variety (of content, voices, messages) on the one hand, and prescribe regularity on the other hand. These mechanisms are made all the more visible because, in both examples, the page sizes remain about the same, displaying generic kinship: the illustrated magazine format requires large pages to present illustrations in an optimal way, and both books are (precocious) instances of large-size publications (Chéroux 18). The fact that these latter characteristically displayed fewer images in this same space, however, showed how they negotiated similarity and difference, and the said pictures appeared, comparatively, if not always larger in size, always so in importance.

Furthermore, magazine examples have demonstrated the resistance of the format: photographs have had to fit in magazines' format conditions which derived from the respective editorial imperatives that have effectively shaped them - all the more so in illustrated fashion and news magazines, in which the production and arrangement of photographs is the core activity and allows for the expression of the magazines' identity. Because of their defining periodicity, magazines are especially fit to exert format rules through serialized repetition (from issue to issue and beyond). Because of their characteristic miscellaneity in contents, a certain formalization of their arrangements is all the more crucial to produce some sense of an overarching identity of the title.

In books however, exposed miscellaneity is the exception, and the continuous and homogenous development of the content is the conventional expectation. In photobooks (a particular "genre" in the book market), displaying photography in a distinctively unmiscellaneous manner is the purpose. As Martin Parr and Gerry Badger, authors to a seminal series of books mapping out photobooks put it: "A photobook is a book - with or without text - where the book's primary message is carried by photographs." (6) $)^{36}$ To qualify as a "photobook" in their strong, narrow acceptation of the word, Parr and Badger consider that a book should melt photographic pictures into an aesthetic, meaningful whole, in short: into a unified work. Images à la sauvette coalesced these parameters in a striking way, accounting for its seminal standing in photobook history. Together with Photographs of a Decade, it participated in establishing format conventions for monographic books by applying "art book" conventions to new photographic genres (such as fashion and beauty images or photoreportages), which made them groundbreaking. In turn, they contributed to legitimize the monographic book, and their posterity made it a reflexive space for thinking about "good" photography - a space which offers the right format conditions to do so, with its long texts separated from its long series of pictures. They also enacted new book format conventions which came to signal artistic intent; and gave photography a new visibility by formatting it into an already well-recognized object. Here, it should be noted that both examples evidence shared networks of production between both media. Actors from the publishing industries were well-aware of the differing magazine and book format conditions. Their personal and professional trajectories intersecting, these actors worked to hierarchize media through format in order to make a cultural point. As the monographic photobook stabilized as a genre, it altered ways of contemplating 
editorial photographs in ways we should turn our attention to, in order to grasp the complex operations behind the solidification of what we call "photography."

Bringing the concept of "the work of format" into the study of printed photography, and unfolding it through in-depth observation encompassing production studies and content analysis allow us to touch upon the textured complexity of photographic uses, which is coming more and more into view in the historiography of photography. By establishing and adhering to a format, the medium, and past media, efficiently played their roles and became characteristically unnoticeable, covering their traces that can nevertheless still be found, engrained within the format and format transfers. A principal task of format research is thus to reconstruct which format conditions and conventions are valid at specific times in the history of print media. This implies turning our attention not to what is striking and exceptional about a certain print publication or about an element in it, but to what connects it tacitly to earlier instances of the medium, genre or title.

Conversely, when focusing on particular cases, the concept of format is a valuable tool to think about the different manifestations of a picture or text, particularly when they are circulating in-between media. A picture or a text that is republished, and manifests in different material forms and different formats, does not remain the same, but is reinvented or reactualized. The approach of material philology, originally developed for the study of manuscript culture, contends that every manifestation of a text is a performance of its own, the material appearance of which must be taken into consideration as an important factor in granting it meaning (Kaminski and Ruchatz 15-25). If we apply this insight to print culture, every new publication of a text or a picture should be considered as an important performance, to be observed with renewed attentiveness, including considerations on its underlying, "invisible" but formative format conditions.

\section{BIBLIOGRAPHY}

\section{Photobooks Cited}

BRASSAÏ. Brassaï. Paris: Éditions Neuf, 1952.

CARTIER-BRESSON, Henri. Images à la sauvette / The Decisive Moment. Paris: Verve / New York:

Simon \& Schuster, 1952.

DOISNEAU, Robert. La Banlieue de Paris. Paris: Seghers, 1949.

EVANS, Walker. American Photographs. New York: The Museum of Modern Art, 1938.

HALL-DUNCAN, Nancy. Histoire de la photographie de mode. 1978. $2^{\text {nd }}$ ed. Paris: Chêne, 1987.

HORST, Horst P. Horst: Photographs of a Decade. New York: J. J. Augustin, 1944. 
HOYNINGEN-HUENÉ, Georg. Meisterbildnisse. Frauen, Mode, Sport, Künstler. Berlin: Dietrich Reimer, 1932.

MAN RAY. Man Ray: Photographs, 1920-1934, Paris. Hartford, Connecticut: James Thrall Soby, 1934.

RENGER-PATZSCH, Albert. Die Welt ist schön. Munich: Kurt Wolff Verlag, 1928.

ROH, Franz (ed.). Aenne Biermann, 60 Fotos / 60 Photos / 60 Photographies. Fototek series. Berlin: Klinkhardt \& Biermann, 1930.

ROH, Franz (ed.). Lazlo Moholy-Nagy, 60 Fotos / 60 Photos / 60 Photographies. Fototek series. Berlin: Klinkhardt \& Biermann, 1930.

SEYMOUR, David. Children of Europe. Paris: UNESCO, 1949.

\section{Magazines Cited}

"A Last Look at Peiping. Photographs for Life by Henri Cartier-Bresson" and "City Finds Serenity in Birds and Boxing." LIFE 26:1 (January $\left.3^{\text {rd }}, 1949\right): 13-21$.

BORELLI, Laird. "Fashion: Fashion Forward.” Vogue U.S. (July 2002): 150-167.

BOWLES, Hamish. "Vogue View: Horst P. Horst, 1906-1999, The Legendary Photographer Who Died Last November, Was A Guiding Light at Vogue for Six Decades.” Vogue U.S. (February 2000): 149-150, 154

“C'était hier." Vogue Paris (December 1939): 34-35. URL: https://gallica.bnf.fr/ark:/12148/ bpt6k65426414/f36.double (page accessed 14 June 2021).

“Grâce de tous les drapés.” Vogue Paris (April 1938): 54-55. URL: https://gallica.bnf.fr/ark:/12148/ bpt6k936228j/f273.double (page accessed 14 June 2021).

"Sugar and Spice in the Paris Collections - Second Report on the Spring Openings." Vogue U.S. (March 15 $\left.{ }^{\text {th }}, 1938\right)$ : 70-78, 159-161.

Vogue U.S. 94:6 (September $\left.15^{\text {th }}, 1939\right)$ : complete issue.

VREELAND Diana. "People Are Talking About: Photographers in Vogue: Horst - the Aura of Glamour.” Vogue U.S. (October 1984): 638, 702-703.

\section{Works Cited}

BAIR, Nadya. "The Decisive Network: Producing Henri Cartier-Bresson at Mid-Century." History of Photography 40:2 (2016): 146-166.

BAIR, Nadya. The Decisive Network: Magnum Photos and the Postwar Image Market. Oakland: University of California Press, 2020.

BEETHAM, Margaret. "Towards a Theory of the Periodical as a Publishing Genre". Investigating Victorian Journalism. Ed. Laurel Brake, Aled Jones and Lionel Madden. Basingstoke: Palgrave Macmillan, 1990. 19-32.

BOUVERESSE, Clara. Histoire de l'agence Magnum. L'art d'être photographe. Paris: Flammarion, 2017.

CHANDLER Daniel and Rod MUNDAY. "Format ». Oxford Dictionary of Media and Communication. 2011. Oxford: Oxford University Press, 2020 ( $3^{\text {rd }}$ ed.) URL: https://www.oxfordreference.com/ 
view/10.1093/acref/9780198841838.001.0001/acref-9780198841838-e-1034 (page accessed 14 June 2021).

CHÉROUX, Clément. “Une bible pour les photographes." Henri Cartier-Bresson. Images à la sauvette. Göttingen: Steidl, 2014 (facsimile edition). 3-31.

GERVAIS, Thierry (in collaboration with Gaëlle MOREL). The Making of Visual News: A History of Photography in the Press. 2015. London: Bloomsbury, 2017.

GERVAIS, Thierry. "Photography. A Design Tool for the Nineteenth-Century Illustrated Press?" Visuelles Design. Die Journalseite als gestaltete Fläche. / Visual Design. The Periodical Page as a Designed Surface. Ed. Andreas Beck et al. Hannover: Wehrhahn, 2019. 137-154.

HICKS, Roger W., Michael PRITCHARD and Graham SAXBY. "Format, Plate and Film". The Oxford Companion to the Photograph. Ed. Robin Lenman. Oxford: Oxford University Press, 2005. 228-229.

JAEGER, Roland. "Bücher der Neuen Fotografie. Die Reihe Fototek im Verlag Klinkhardt \& Biermann, Berlin.” Autopsie. Deutschsprachige Fotobücher 1918 bis 1945 (vol. 1). Ed. Manfred Heiting and Roland Jaeger. Göttingen: Steidl, 2012. 332-343.

KAMINSKI, Nicola and Jens RUCHATZ. Journalliteratur - Ein Avertissement. Hannover: Wehrhahn, 2017.

LAW, Graham. Serializing Fiction in the Victorian Press. Basingstoke; New York: Palgrave, 2000.

LAWFORD, Valentine. Horst: His Work and his World. New York: Alfred A. Knopf, 1984.

LUHMANN, Niklas. Social Systems. 1984. Stanford: Stanford University Press, 1995.

MCGILL, Meredith L. "Format." Early American Studies. An Interdisciplinary Journal 16:4 (2018): 671-677.

MEIZEL, Laureline. “Images à la sauvette' et papiers gras ou pourquoi et comment se salir les doigts. Méditations sur le photobook, d'après l'exposition de la fondation Henri Cartier-Bresson (11 janv. - 23 avr. 2017)" (Part I). Carnet Hypothèses de l'ARIP (April 1 $\left.{ }^{\text {st }}, 2017\right)$. URL : https:// arip.hypotheses.org/1760 (page accessed 14 June 2021).

MEYER, Roland. “Gesichtsbildformate 1860/1960. Disdéri, Warhol und der Primat der Zirkulation." Format. Politiken der Normierung in den Künsten ab 1960. Ed. Magdalena Nieslony and Yvonne Schweizer. München: edition metzel, 2020. 170-183.

MOERAN, Brian. “More Than Just a Fashion Magazine.” Current Sociology 54:5 (September 2006): 725-744.

MÜLLER, Susanne. “Formatieren.” Historisches Wörterbuch des Mediengebrauchs. Ed. Heiko Christians, Matthias Bickenbach and Nikolaus Wegman. Cologne; Weimar; Vienna: Böhlau, 2015. 253-267.

MUSSELL, James. The Nineteenth-Century Press in the Digital Age. Basingstoke: Palgrave Macmillan, 2014.

NIEHAUS, Michael. Was ist ein Format? Hannover: Wehrhahn, 2018.

PARR, Martin and Gerry BADGER. The Photobook: A History (Vol. 1). London: Phaidon, 2004.

PROSS, Harry. Medienforschung. Film, Funk, Presse, Fernsehen. Darmstadt: Habel, 1972.

RITCHIN, Fred and Carole NAGGAR. Magnum Photobook: The Catalogue Raisonné. London: Phaidon, 2016. 
RUCHATZ, Jens. "Kontexte der Präsentation. Materialität und Medialität des fotografischen Bildes.” Fotogeschichte 32:124 (2012): 19-28.

SCHULZ, Hans and Otto BASLER. Deutsches Fremdwörterbuch (Vol. 5). 1995. $2^{\text {nd }}$ ed. Berlin: De Gruyter, 2004.

SICHEL, Kim. Making Strange: The Modernist Photobook in France. New Haven: Yale University Press, 2020.

SPOERHASE, Carlos. Das Format der Literatur. Praktiken materieller Textualität zwischen 1740 und 1830. Göttingen: Wallstein, 2018.

STERNE, Jonathan. MP3: The Meaning of a Format. Durham: Duke University Press, 2012.

STOLL, Mareike. ABC der Photographie. Photobücher der Weimarer Republik als Schulen des Sehens. Köln: Buchhandlung Walther König, 2018.

VAN DE CASTEELE, Marlène. “FROG, un magazine transatlantique, 1920-1938." Vogue Paris, 100 ans. Ed. Sylvie Lécallier. Paris: Paris Musées, 2021 (forthcoming).

VOLMAR, Axel. "Das Format als medienindustriell motivierte Form." Zeitschrift für Medienwissenschaft 22 (2020): 19-30. URL: https://doi.org/10.25969/mediarep/13641 (page accessed 14 June 2021).

VOLMAR, Axel, Marek JANCOVIC and Alexandra SCHNEIDER. "Format Matters: An Introduction to Format Studies." Format Matters: Standards, Practices, and Politics in Media Cultures. Ed. Marek Jancovic, Axel Volmar and Alexandra Schneider. Lüneburg: Meson Press, 2020. 7-22.

WILCOX, Claire. "The Aura of Glamour: Couture Fashion." Horst: Photographer of Style. Ed. Susanna Brown. London: V\&A Publishing, 2014. 62-93.

ZERVIGÓN, Andrés Mario. "Rotogravure and the Modern Aesthetic of News Reporting." Getting the Picture: The Visual Culture of News. Ed. Jason E. Hill and Vanessa R. Schwartz. London: Bloomsbury, 2015. 197-205.

\section{NOTES}

1. Monographic photobooks, i.e., non-thematic books centered on a single photographer's work, were scarce before the 1950s. Notable exceptions include Man Ray's Man Ray: Photographs, 1920-1934 (1934) or Walker Evans' American Photographs (1938), yet both started out as retrospective exhibition catalogues. Albert RengerPatzsch's Die Welt ist schön (1928) presents similarities with Photographs of a Decade, insofar as it does not distinguish between artistic and commercial work. However, closest to it is Horst's mentor and predecessor as Vogue in-house photographer, Georg Hoyningen-Huené's Meisterbildnisse. Frauen, Mode, Sport, Künstler (1932), nonetheless more confidential in scope and distribution.

In Germany, Klinkhardt \& Biermann also published, in the collection Fototek, two titles gathering photographs by Laszlo Moholy-Nagy and Aenne Biermann in a monographic way, both simply titled 60 Fotos / 60 photos / 60 photographies (Roh 1930); on the subject, see Jaeger.

2. Converging endeavors, mostly from humanist photographers, coincided with Cartier-Bresson's around the same time. See for instance Robert Doisneau's La Banlieue de Paris (1949), David Seymour's Children of Europe (1949), or Brassaï's Brassaï (1952). 
However, most remained thematic books and were less unified; and none has met quite the same success in photographic circles - perhaps as a result.

3. Horst's book, while strongly fashion-oriented, also includes more highly regarded photographic genres, such as society or artists' portraits, any of which could have made for a more conventional cover choice.

4. With regard to literature, Spoerhase proposes to study "text careers" (32-33). For a plea to "follow" photographs across all of their contexts and materializations, see Ruchatz (27).

5. These two cases studies have been conducted as part of a larger ongoing research project by the authors, with a corpus covering six decades and a variety of genres (news, fashion and sport). The project traces how the respective mediality of magazines and book are performatively constructed in the $20^{\text {th }}$ century, through instances where photographs transfer from one to the other. Format conventions, of course, play a major part in such mediatic processes.

6. Vogue, founded in 1892 and developed under Condé Nast who bought the magazine in 1909, was already an influential fashion publication by 1938: published in three national editions (American, British and French), it was altogether an important point of reference for the fashion trade and an aspirational title, on account of its affirmed position on the high-end press market.

LIFE relaunched in 1936 under the direction of Henry Luce, who sought to make it a model for the illustrated news press. It soon came to surpass its inspirations, the French $V U$ and the German Berliner Illustrierte Zeitung, due to its heavy investments in photographic reportages and its popularization and expansion of the innovative layout practices of its predecessors.

Both publications have been the focus of growing scholarly attention in the last decades.

7. The first documented uses of the term with reference to book production go back as early as $16^{\text {th }}$-century Germany (Schulz and Basler 1027-30) and $18^{\text {th }}$-century France. In English, the term became commonly used in the mid-19 ${ }^{\text {th }}$ century only. For a concise history of the concept of "formatting" (mainly in the German context), see Müller (254-61).

8. For a recent reading of the carte-de-visite as a format for picture circulation, see Meyer (172-75).

9. In this respect, German communication scholar Harry Pross makes a useful distinction, with regard to the technicization of media communication, between primary media (requiring no technology at all), secondary media (using technology in production) and tertiary media (necessitating technology in production and reception) (10-11).

10. The fact that print formats are less bound by technology than tertiary media's also makes it easier for innovations in magazines or books to emerge: the number of pages, for instance, as well as their size, can vary greatly from one production to the other, which it often does for purposes of differentiation. Of course, it has sometimes been the case, as with the much-quoted "stamp duty" imposed by the British parliament on certain periodical publications during the $18^{\text {th }}$ and $19^{\text {th }}$ centuries, that powerful external factors have impacted the shape of print media formats - if only by prompting the print industry to come up with creative alternatives (Law 1-13). 
11. For a theoretical reflection on the interrelation of miscellaneity and seriality as foundational characteristics of the periodical, see Mussell (30, 49-56).

12. For a general reflection on the relevance of reflexive expectations for social relations, see Luhmann (304-7).

13. These concepts are introduced in Kaminski and Ruchatz (31-32).

14. Para-texts (or -images), expanding on Gérard Genette's concept, are conceptualized as texts or images spatially related to those under study, via a relation of contiguity. Peritexts (or -images), in turn, refer to other texts or images on the double page, in the journal issue or throughout a continued series of publications, which are directly related to the one(s) under study (Kaminski and Ruchatz 32-33).

15. See here: https://www.tampabay.com/things-to-do/visualarts/review-horst-phorsts-elegant-photographs-stand-test-of-time-at-dali-museum/2288127/ for the magazine version; and here: https://andthings.exblog.jp/19951108/ for the book version of the image.

It was also set to appear in the October 1939 issue French Vogue but, in the context of World War II, it was never published. The photograph was nevertheless included in a December 1939 unusual double page (34-35): https://gallica.bnf.fr/ark:/12148/ bpt6k65426414/f36.double, which staged photographs as memories, while linking them to the materiality of magazine-making, and to the different temporalities they connect.

16. Two versions of the photograph co-exist today, one with a tighter lacing apparently resulting from magazine editing, and the second where the corset is looser on the model's body (from the photographer's personal collection, see Wilcox 76). The former was the one reproduced in Photographs of a Decade, upholding the magazine's editorial choice unto the book form.

17. In the $19^{\text {th }}$ century, pictures were reproduced in magazines and books by way of wood engraving. Their size had to be determined long before the printing started, to allow for the time-consuming production of the printing blocks. Besides, publishers tried to recoup their expansive investment, reproducing these blocks as stereotypes and electrotypes sold for re-use to other publishers. The layout thus always had to be organized around the pictures, the size of which could not be altered, which limited interplay between pictures and letterpress. Photomechanical methods of reproduction, e.g., the half-tone processes introduced in the 1880s, represented a major shift, as the transfer of the picture to be reproduced to the printing plate was not performed by material contact but by exposure. This made the half-tone a "design tool" in the first place (Gervais 2019) and granted new flexibility to print media layouts, while until the 1920s, photographic positives were generally printed by contact, inscribing the negative format into the size of the positives (Hicks et al. 228-29). The introduction of rotogravure printing made the arrangement of pictures - e.g., the tilting of images ever more flexible (Zervigón; Gervais 2017, 100).

18. In latter pages of the issue, sketches (unsigned) of the Detolle corset photographed in the Collection report are further provided (142-43).

19. The book's page measures are $23.7 \times 30.7 \mathrm{~cm}$; the magazine's, $23.5 \times 31.5 \mathrm{~cm}$. Maintaining an equally large size for the photograph in the book also ensures that its impact does not fall short compared with its precursor in the magazine.

20. The paper used by the magazine is about the same grammage, but it is far glossier. The more legible shading of the Corset in Vogue agrees with a glossy paper, whilst the 
matte paper of the book allows legibility for this more contrasted version. The same reproduction technique, that of the half-tone, is employed in both.

21. This would, of course, be unfathomable in a fashion photograph, designed to promote this very element.

22. The Magnum agency, a photojournalist-owned cooperative, was established in order to give its members more weight in the press industry and more control over the publication of their production (Bair 2020, 13-26). Magnum's creation was thus an important step in reshaping photographic-media practices and in collectively defining photography's status throughout media formats.

23. This background accounts for Cartier-Bresson's upholding of a cultural hierarchy that classically differentiates between art and commerce. He worked to reposition his work within this hierarchy, by positing that journalistic work (which could be looked down upon as commercial work) can cohere into an artistic corpus and demonstrate formal creativity (Bouveresse 87-89). The publication of Images à la sauvette is an important step in that direction.

24. The article, unsigned, quotes Cartier-Bresson at length, thus making him the only identifiable "voice" throughout, in visual and textual terms.

Magnum was instrumental in ensuring that captions in magazines faithfully reproduced its photographers' words, which explains the coherence of such peritext from one publication to the other.

25. The size of an issue of LIFE magazine is $26.7 \times 35.5 \mathrm{~cm}$, just a bit smaller than the book.

26. Still in the introduction, Cartier-Bresson pictures himself as wary of photographers trying to "make art" $(3,8)$, while a section is devoted to "Technique" (and the American edition even includes a technical booklet). Cartier-Bresson thus does not explicitly position photography as an art; however, the book itself, with its specific choices, does loudly express artistic pretentions.

27. In a paragraph of his introductory essay to The Decisive Moment, curiously only included in the US edition, Cartier-Bresson links photobook and exhibitions: "There are ways of communicating our photographs other than through publication in magazines. Exhibitions, for instance; and the book form, which is almost a form of permanent exhibition" (13).

28. Tériade, publishing artistic revues and monographs by renowned artists such as Matisse, but also Marc Chagall or Henri Laurens, was not a photobook publisher Images à la sauvette is actually the only one that he produced, along with CartierBresson's succeeding Les Européens (1955).

29. The Decisive Moment's American publisher, Richard Simon, was at first surprised, and highly skeptical of this choice for the book cover, demonstrating how it represented a format irregularity (Bair 2016, 157).

30. The master craftsmen responsible for the printing of both editions - the Draeger brothers - are acknowledged on the title page.

31. Such an idea is already to be found in German experiments around the photobook form in the 1930s. On the subject, see Stoll.

32. There is one notable exception in the section as a 1946 photograph of a garden in France is included. However, it only seems to further signal that the chronological- 
geographic ordering is above all the product of the photographer's sensibility and subjectivity.

33. On Magnum photographers and "humanist photography," see Bouveresse (75-81); Sichel (125-37); Bair (2020, 4-6).

34. This conclusion pertains to a given historical moment, of course; it is highly unlikely that a study of $19^{\text {th }}$-century photographic transfers would yield such a result. In our case studies, this can be tentatively explained because, at the time, the bulk of the photographs transferring from magazine to books were the ones standing at the top of the magazines' pictorial hierarchy, which appears to be especially true for photographs republished in auctorial monographic photobooks.

35. For a theoretical reflection of the different levels and forms of context brought to bear on photographic meaning, see Ruchatz.

36. A collection of singled-out photobook examples, The Photobook: A History effectively operated a canonical selection in the arborescent and elusive larger field of photographically-illustrated books. Images à la sauvette was included, while Photographs of a Decade, far more understudied, and standing at the margins of this canon, was not.

\section{ABSTRACTS}

This paper deals with photography in illustrated magazines and photobooks, and with what unfolds when photographs migrate from one media to the other. In such instances, we argue, reformatting is performed in distinctive affordances; yet such transfers also make visible the format conditions that underlie both the magazine and book media. By conducting an in-depth analysis of two exemplary photographs, by Horst P. Horst and Henri Cartier-Bresson, circulating between magazines and books, we aim to show how format markedly shapes photography in print and thus to demonstrate the work of format. In the process, matters of authoring and reappropriating, as well as mechanisms of canonization and/or memorialization are brought to light. All contribute to structure and solidify the photographic field, as well as periodicals and books as media, in relationship to one another (and to their mediatic content). The established hierarchy of formats, in which photographs move up from magazines to books, in fact proved beneficial to both, bolstering the distinction - and thus the identity - of the media book and periodical.

Cet article se penche sur la photographie telle qu'elle circule au sein de la culture imprimée, depuis la presse magazine jusqu'aux photobooks. Plus précisément, il s'intéresse aux transferts photographiques entre les magazines et les ouvrages monographiques. De telles republications offrent des configurations uniques, au sein desquelles se déploient des interprétations singulières de ce que le format permet. Dans le même temps, ces cas particuliers manifestent les conventions liées au format propres à chaque médium et qui le sous-tendent. L'analyse de deux photographies publiées successivement dans des magazines puis dans des livres monographiques met en évidence la manière dont le format conditionne les présentations successives de images considérées ; c'est-à-dire que ces deux études de cas montrent le format à l'œuvre. Ces transferts mobilisent des processus d'auctorialité, de réappropriation, ainsi que des mécanismes de 
mémorialisation et/ou de canonisation - tous enjeux qui contribuent à façonner le champ photographique, ainsi que les magazines et les livres comme sites médiatiques distincts mais associés. En effet, la hiérarchie culturelle qui s'établit entre magazines et photobooks - les photographies s'élevant en passant des premiers aux seconds - fonctionne finalement au bénéfice de l'un comme de l'autre médium, qui y assoient leur identité respective.

\section{INDEX}

Mots-clés: magazines illustrés, photobooks, livre monographique, photographie de presse, photographie de mode, photojournalisme, Horst P. Horst, Cartier-Bresson (Henri), Vogue, LIFE, Photographs of a Decade, Images à la Sauvette

Keywords: illustrated magazines, monographic photobooks, photography in print, media formats, Horst P. Horst, Cartier-Bresson (Henri), Vogue, LIFE, Photographs of a Decade, Images à la Sauvette

\section{AUTHORS}

\section{ALICE MORIN}

Philips-Universität, Marburg - Journaliteratur

Alice Morin is postdoctoral research associate to the "Fragmentwanderungen" project. In 2018, she was awarded a PhD in American Studies by Université Sorbonne Nouvelle, where she also taught American history. Her research focuses on the mediatic uses of photographs, and their production and circulation in a transnational context. She is also currently the scientific advisor for the French Vogue centennial exhibition, which will open at the Palais Galliera-Musée de la Mode de la Ville de Paris in the fall of 2021. Project A Media-Based Comparison of Fragment Migration: Photographs in Periodicals and Books in the Twentieth Century: https:// journalliteratur.blogs.ruhr-uni-bochum.de/gb/fragmentwanderungen-im-medienvergleichfotografien-in-zeitschrift-und-buch-im-20-jahrhundert-tp-5-2/

\section{JENS RUCHATZ}

Philips-Universität, Marburg - Journaliteratur Jens Ruchatz is professor of media studies at Philipps-University Marburg and leads the research project "Fragmentwanderungen/Fragment Migrations" in the research unit "Journalliteratur/ Journal Literature." His research addresses a broad spectrum of media, from the telegraph and television to the various manifestations of photographic pictures. His current research interests include the media history of the interview, food and media, serial structures in media, photography in print and picture practices in social media. Project A Media-Based Comparison of Fragment Migration: Photographs in Periodicals and Books in the Twentieth Century: https:// journalliteratur.blogs.ruhr-uni-bochum.de/gb/fragmentwanderungen-im-medienvergleichfotografien-in-zeitschrift-und-buch-im-20-jahrhundert-tp-5-2/ 